\title{
Apical extrusion of sodium hypochlorite activated with two laser systems and ultrasonics: a spectrophotometric analysis
}

Bağdagül Helvacıoğlu Kıvanç ${ }^{*}$, Hacer Deniz Arısu², Nazlı Özge Yanar ${ }^{1}$, Hülya Mercan Silah ${ }^{3}$, Recai İnam ${ }^{4}$ and Güliz Görgül ${ }^{1}$

\begin{abstract}
Background: The aim of the present study was to compare the effect of ultrasonically or laser (Nd:YAG or diode) activated irrigation on the irrigating solution extrusion compared to non-activated syringe irrigation.

Methods: Extracted mandibular premolar teeth $(n=48)$ with single canals were instrumented. The teeth were secured through the lid of an Eppendorf tube filled with $1.0 \mathrm{~mL}$ distilled water to collect the apically extruded irrigating solution. The teeth were randomly divided into four groups: non-activated syringe irrigation, diode laser, Nd:YAG laser and passive ultrasonic irrigation (PUI) using $2 \% \mathrm{NaOCl}$. The irrigating solution extruded through the apical foramen was collected in the Eppendorf tube and evaluated by a chemical reaction with using a spectrophotometer. The data was analyzed using one-way ANOVA and Tukey's post hoc test $(a=0.05)$.
\end{abstract}

Results: All the groups showed apically extruded irrigating solution. There were significant differences among the groups ( $p<0.05)$. Nd:YAG laser activated irrigation showed greater extrusion $(p<0.05)$, while the non-activated syringe irrigation showed less extrusion $(p<0.05)$. Only the difference between diode laser and PUI was not statistically significant $(p>0.05)$.

Conclusion: Within the limitations of this in vitro study, the researchers concluded that non-activated syringe irrigation caused less apically extruded irrigating solution than PUI and LAI using Nd:YAG or diode lasers.

Keywords: Apically extruded irrigating solution, Diode laser, Nd:YAG laser, Passive ultrasonic irrigation, Sodium hypochlorite

\section{Background}

Root canal irrigation plays an important role in the debridement and disinfection of the root canal system [1]. The goal of irrigation is to remove pulp tissue and/or microorganisms (planktonic or biofilm) from the root canal system [2]. Irrigation is also used to eliminate the smear layer and dentin debris, which occur following instrumentation of the root canal [3]. Sodium hypochlorite at various concentrations is widely used as an endodontic disinfectant thanks to the chemical properties of the pulp dissolution, effective antimicrobial action, dissolution of organic material,

\footnotetext{
* Correspondence: bagdagulkivanc@gmail.com

${ }^{1}$ Gazi University Faculty of Dentistry Department of Endodontics, 8. Cadde 82. Sokak, 06510 Emek-Ankara, Turkey

Full list of author information is available at the end of the article
}

transformation of amines into chloramines, and deodorizing effects [4-6].

The mechanical and chemical effectiveness of an irrigation regimen depend on the working mechanisms of the irrigating solution and the ability to bring the irrigating solution in contact with those elements, materials, and structures within the canal system that should be removed [7]. Syringe irrigation is the standard procedure; however, it is not effective in the apical part of the canal [8] and in the isthmus and oval extensions [9]. Moreover, predictable delivery of irrigants to the working length with needle irrigation is not often attained [10]. Nonetheless, some studies suggest that the tip of an injection needle should be placed as close as possible to the apical end of the canal to clean the entire root canal length effectively [10-12]. However, it may 
increase the risk of extrusion of the solution [13]. As the irrigating solutions are usually cytotoxic, the possibility of an accidental extrusion beyond the apical construction should be considered during root canal irrigation.

Passive ultrasonic irrigation (PUI) was first described by Weller et al. [14]. When a small file or smooth wire placed at the center of the root canal that does not contact the canal wall is activated ultrasonically, 'acoustic streaming' occurs. As the root canal is enlarged, the file or wire can vibrate freely in a way to enable acoustic streaming, thereby transferring its energy to the irrigating solution throughout the canal [15]. Various studies have shown that $\mathrm{NaOCl}$ used with PUI removes more dentin debris, planktonic bacteria, and pulp tissue from the root canal compared to syringe irrigation $[16,17]$.

Laser-activated irrigation (LAI) has been introduced as a powerful method for root canal irrigation. Past work has shown that solid-state laser systems with short pulse durations can induce pressure waves in water, including the near-infrared Nd:YAG laser [18] and more recently the middle infrared Er:YAG and Er,Cr:YSGG lasers [19, 20] These laser-generated pressure waves move at high speed, with different characteristics from waves induced by freely vibrating sonic and ultrasonic endodontic instruments [18] and appear to enhance the action of endodontic irrigating solutions in terms of smear layer removal [21]. In the study of Hmud et al. [22] laser-induced cavitations with nearinfrared diode lasers was shown in a glass capillary tube model. The laser radiation produces transient cavitation in the liquid through the optical breakdown by absorption of the laser energy. Laser-activated irrigation may result not only in the removal of the smear layer from the root canal wall, but also extrusion of irrigating solution through the apex $[20,21]$.

The aim of the present study was to compare the effect of ultrasonically or laser (ND:YAG or Diode) activated irrigation on the irrigating solution extrusion compared to non-activated syringe irrigation (control).

The null hypothesis was that the activation methods did not result in more apical extrusion than the control group.

\section{Methods}

This study was approved by Ethics Committee of Ankara University Faculty of Dentistry, Turkey, in accordance with the Declaration of Helsinki (Reference number:36290600/121).

For this study, forty-eight $(\mathrm{N}=48)$ freshly extracted single-rooted human mandibular premolar teeth with single canals were collected from the Clinic of the Department of Oral and Maxillofacial Surgery, Faculty of Dentistry, Gazi University of Ankara, Turkey. The teeth with straight root canals of similar size were included to reduce the effects of canal size and curvature on the extrusion of the irrigant. Radiographic images from the buccal and proximal aspects for each sample were exposed. The teeth with an open apex in the radiographic images were excluded from the study.

Following extraction, the teeth were stored for two days in $3 \% \mathrm{NaOCl}$ at room temperature to remove organic debris. They were scaled with ultrasonics, washed with distilled water to remove any calculus or soft tissue debris, and then immersed in $10 \%$ formalin solution until use.

The teeth were decoronated to obtain root segments of 14-mm in length. A 10-K file (Antaeos; Vereinigte Dentalwerke $\mathrm{GmbH}$ \& Co, Munich, Germany) was placed into the canal until it was visible at the apical foramen. The working length was established as $0.5 \mathrm{~mm}$ short of this length.

The root canal preparation was performed using rotary instruments (ProTaper, Dentsply, Maillefer, Ballaigues, Switzerland) with a crown down technique. Apical instrumentation was completed with a F3 file (ISO size 30, taper 0.09-0.05). Between the instruments, each canal was irrigated with $2 \mathrm{~mL}$ of $2 \% \mathrm{NaOCl}$ solution using a syringe and 27-gauge needle. Apical patency was checked with a size 10-K file between each instrument. The teeth were secured with self-curing acrylic resin through the lid of an Eppendorf tube filled with $1.0 \mathrm{~mL}$ distilled water to collect the apically extruded irrigating solution. 27-gauge needle was inserted into the Eppendorf tube to equalize the pressure inside and outside the tube (Fig. 1)

The volume of the irrigating solution was kept constant as $4 \mathrm{~mL}$ for all control and experimental groups.

Non-activated syringe irrigation (Control group): $4 \mathrm{~mL}$ of $2 \% \mathrm{NaOCl}$ was injected into the root canals in $60 \mathrm{~s}$ with a 27 -gauge open-end tip needle, which was placed 2-mm short of the working length without binding (with a constant fluid flow rate of $0.7 \mathrm{~mL} / \mathrm{sec}$ ).

LAI using diode laser (Pocket Diode Laser, Orotig, Verona, Italy): the diode laser $(915 \mathrm{~nm}, 1.2 \mathrm{~W}, 200 \mu \mathrm{m}$ fiber optic tip, continuous wave) was activated for a total of $21 \mathrm{~s}(3 \mathrm{X} 7 \mathrm{sec})$.

LAI using Nd:YAG laser (Pulse Master $600 \mathrm{IQ}$, Texas, USA): Nd:YAG laser $(120 \mathrm{~mJ}, 20 \mathrm{~Hz}, 2.4 \mathrm{~W}, 320 \mu \mathrm{m}$ fiber optic tip, pulsed mode) was activated for $20 \mathrm{~s}$.

PUI (Satelec, Acteon Group, Merignac, France): PUI was performed with a piezoelectrical ultrasonic unit with power setting 5. A stainless steel size $15-\mathrm{K}$ file (Satalec) was inserted into the root canal and the irrigating solution was ultrasonically activated for $60 \mathrm{~s}$ [23].

After LAI using diode laser, LAI using Nd:YAG laser and PUI, the root canals were irrigated with $2 \mathrm{~mL}$ of $2 \%$ $\mathrm{NaOCl}$ for $30 \mathrm{~s}$ with a 27 -gauge needle, which was placed $2 \mathrm{~mm}$ short of the working length (with a constant fluid flow rate of $0.7 \mathrm{~mL} / \mathrm{sec}$ ). 


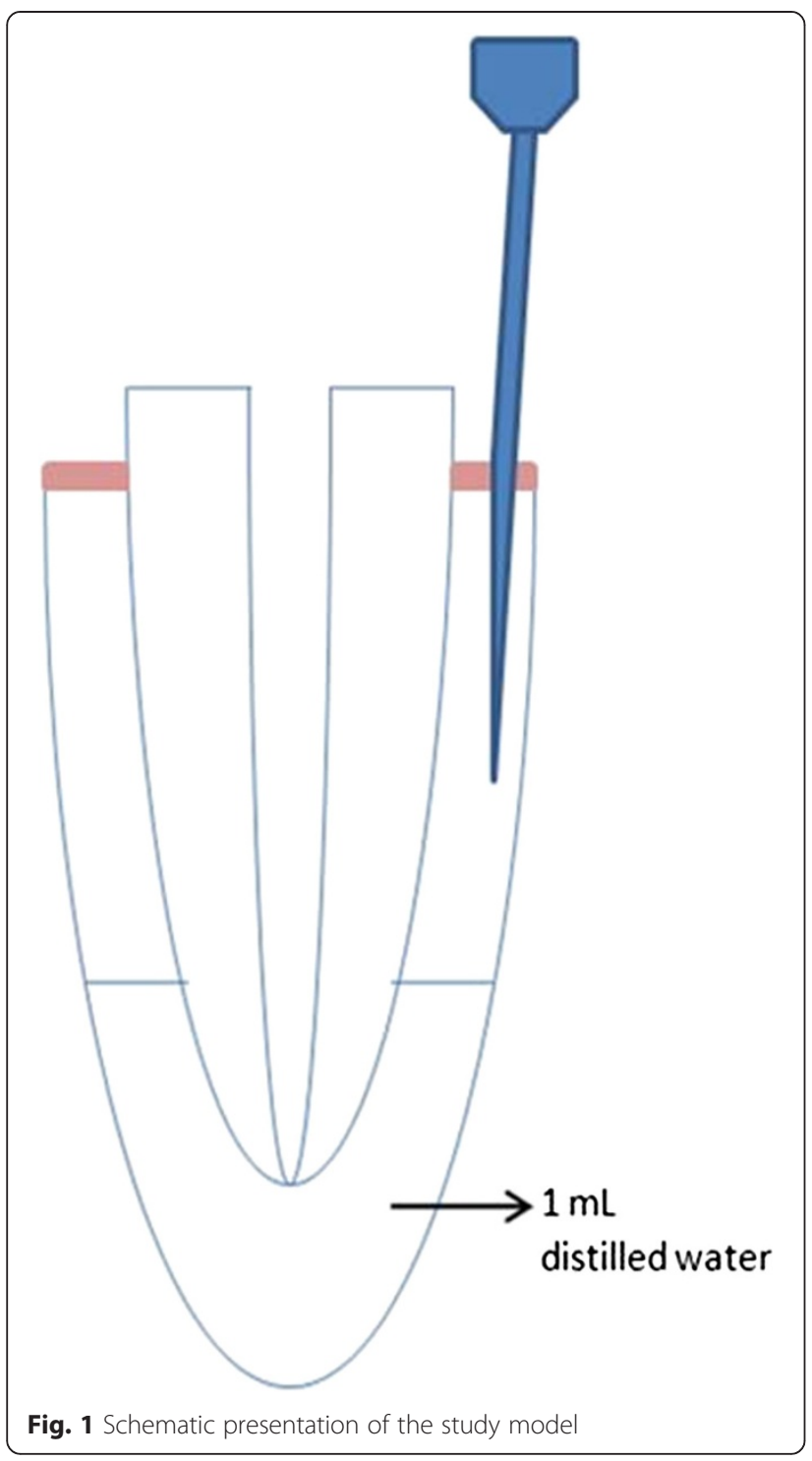

The quantitiy of hydrochloride ion in an aqueous sample can be determined by finding out how much iodine it can produce by oxidizing an iodide ion [24]. The amount of the extruded $\mathrm{NaOCl}$ in the Eppendorf tubes was determined by this chemical reaction of $\mathrm{OCl}^{-}$with $\mathrm{I}^{-}$(iodide) in acidic solution.

$$
\begin{aligned}
& 2 \mathbf{e}^{-}+2 \mathrm{H}^{+}+\mathrm{OCl}^{-} \quad \mathrm{Cl}^{-}+\mathrm{H}_{2} \mathbf{O} \\
& 2 \mathrm{I}^{-} \quad \mathbf{I}_{2}+2 \mathbf{e}^{-} \\
& 2 \mathbf{H}^{+}+\mathbf{O C l}^{-}+2 \mathbf{I}^{-} \quad \mathbf{I}_{2}+\mathbf{C l}^{-}+\mathbf{H}_{2} \mathbf{O}
\end{aligned}
$$

Following the chemical reaction, the amount of $\mathrm{NaOCl}$ was determined by spectrophotometric assessment of the change in color due to the formation of iodine $\left(\mathrm{I}_{2}\right)$ in an aqueous solution with a spectrophotometer (Unicam UV2-100 UV/Visible Spectrometer, Aberdeen, UK). The statistical analysis was performed using one-way analysis of variance (ANOVA) and Tukey's post hoc tests $(\alpha=0.05)$.

\section{Results}

The concentration of the apically extruded irrigating solution is presented in Fig. 2. All the groups showed apical extrusion of irrigating solution. There were significant differences between the groups. $(\mathrm{p}<0.05)$. The non-activated syringe irrigation showed less extrusion, while LAI using Nd:YAG laser showed a greater amount of extrusion. There was only not a significant difference between the LAI using diode laser and PUI ( $\mathrm{p}>0.05)$.

\section{Discussion}

With the aim of comparing the effect of the methods used for improving the efficacy of $\mathrm{NaOCl}$ irrigation, the researchers assessed more apical extrusion of the irrigant as a result of activating the irrigation solution with different systems. The null hypothesis was rejected.

The protocol for this study was designed to maximize the possibility of extrusion of irrigating solution through an unrestricted, yet normal apex. To standardize the apical constriction, apical patency was checked with a size $10-\mathrm{K}$ file between each instrument. All control and activated groups were irrigated from $2 \mathrm{~mm}$ short of the working length with $4 \mathrm{~mL} \mathrm{NaOCl}$ using 27- gauge needle for obtaining a standardization of irrigation. In laser groups the fiber tip was inserted $1 \mathrm{~mm}$ short of the working length as the manufacturers' instructions. In PUI group the file was also inserted $1 \mathrm{~mm}$ short of the working length to obtain standardization between activations. In the present study, each tooth was secured through the lid of an Eppendorf tube filled with distilled water to collect the apically extruded irrigating solution. The amount of extruded $\mathrm{NaOCl}$ in the Eppendorf tubes was determined by the chemical reaction of $\mathrm{OCl}^{-}$with $\mathrm{I}^{-}$(iodide) in an acidic solution. Following the chemical reaction, the amount of $\mathrm{NaOCl}$ was determined by spectrophotometric assessment of the change in color due to the formation of iodine $\left(\mathrm{I}_{2}\right)$ in aqueous solution which is consistent for detecting small increments of extruded material. Various methods have been used to evaluate apical extrusion of irriganting solutions in vitro, however this model provides sensitivity along with quantification of extrusion of irrigating solution [24, 25].

The results of the current study revealed that apical extrusion increased with the activation of sodium hypochlorite irrigation. Non-activated syringe irrigation showed less apical extrusion of irrigating solution than activated methods. Meire et al. [26] found that the absorption coefficient values of $\mathrm{NaOCl}$ at $980 \mathrm{~nm}$ diode laser and $1064 \mathrm{~nm} \mathrm{Nd:YAG} \mathrm{laser} \mathrm{are} 0.250$ and $0.108 \mathrm{~cm}^{-1}$ respectively. These values are well below the absorbtion coefficient values required for occurrence of cavitation at the laser tip $\left(10 \mathrm{~cm}^{-1}\right)$. However, the absorption coefficient of 


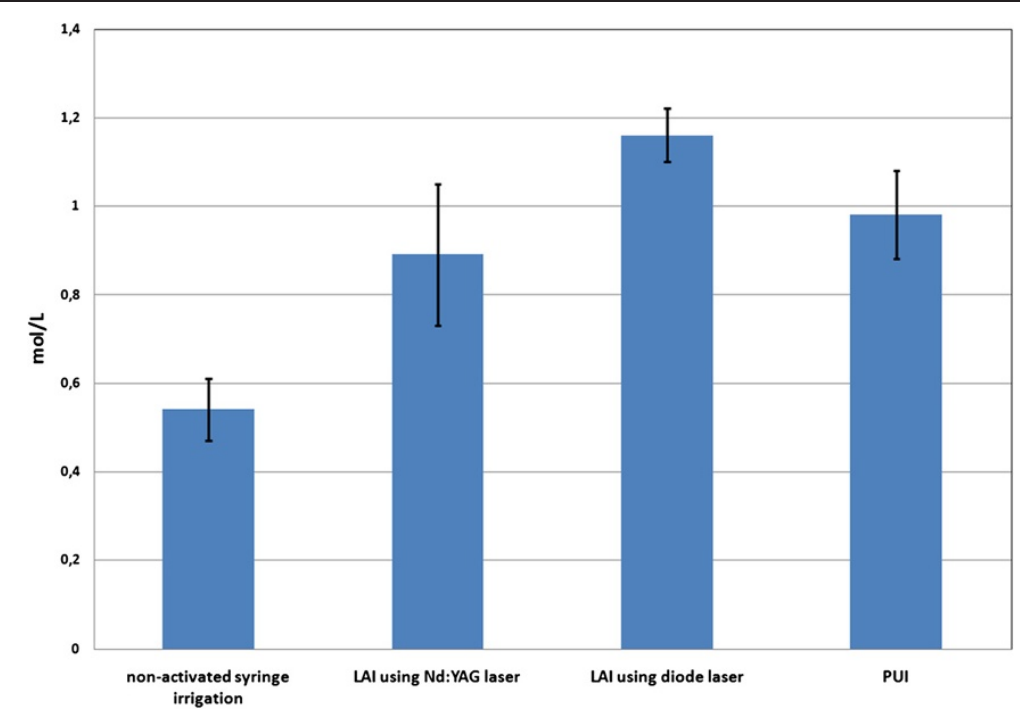

Fig. 2 The concentration of apically extruded irrigant (mol/L)

the irrigation solution is not the only factor that effects the occurance of cavitation at the laser fiber tip. The wavelength, power density and energy density also play a role. It has been suggested that 940-nm and 980-nm diode lasers also are able to induce cavitations and hence activate irrigants [22]. Lauterborn and Ohl [27] produced cavitation bubbles in water using a laser with very low absorption in water (Nd:YAG laser; $1.064 \mathrm{~nm}$ alpha of $0.1 \mathrm{~cm}^{-1} 98 \%$ transmission through $1 \mathrm{~mm}$ ). In this study although apical extrusion occurred with both lasers in different modes, the Nd:YAG laser activation showed a greater amount of extrusion of irrigating solution. As the lasers were used in accordance with the manufacturers' instructions, it may be related to high power setting of Nd:YAG laser. In this study, diode laser was used in a continuous wave, whereas the Nd:YAG laser was used in pulsed mode. Due to the pulsations of the laser, the fluid becomes accelerated at every pulse and the acceleration gives rise to the inertia forces [28]. Pulsed lasers can create pressure waves of sufficient force to propel microdroplets of the aqueous irrigating solution beyond the apical constriction [18]. Thus, caution should be exercised when using such lasers in combination with irrigating solutions such as sodium hypochlorite.

The PUI group also showed apical extrusion of irrigating solution. One of the previous studies showed that systems using ultrasound cleaned the endodontic space more effectively; however, that cleansing action was more difficult to control [29]. There might be a risk of pushing the irrigating solution beyond the apex. The PUI system showed absolute safety when used at 5 and $3 \mathrm{~mm}$, whereas there was some extrusion of $\mathrm{NaOCl}$ in almost all tests at $1 \mathrm{~mm}$ [29]. The result of this study, contradicts an earlier report [30] which concluded that no significant difference was detected between PUI techniques and passive extrusion (control) of irrigating solution. The application time (10 s) of PUI differs from this study (60s). In a spectrophotometric study, RodriguezFigueroa et al. [25] used PUI $2 \mathrm{~mm}$ short from the working length, and concluded that PUI as a safe device. However, in this study we used PUI $1 \mathrm{~mm}$ short from the working length.

\section{Conclusion}

Within the limitations of this in vitro study, the researchers concluded that non-activated syringe irrigation caused less apical extrusion of irrigating solution than PUI and LAI using Nd:YAG or diode lasers..

\section{Abbreviations}

PUI: Passive ultrasonic irrigation; LAl: Laser-activated irrigation; NaOCl: Sodium hypochlorite; Nd:YAG laser: Neodymium-doped yttrium aluminium garnet laser; I2: lodine.

\section{Competing interests}

The authors declare that they have no competing interests.

\section{Authors' contributions}

BHK formulated the conception and design of the study, participated in data acquisition and interpretation of data analysis and prepared the manuscript. HDA participated in the design of the study and interpretation of data analysis and performed the stastistical analysis. NÖY participated in data acquisition. HMS carried out the chemical analysis. Ri contributed to data acquisition and interpretation of the chemical anaysis. GG participated in its design and coordination. All authors read and approved the final manuscript.

\section{Acknowledgements}

This study was funded by Scientific Research Projects Unit of Gazi University.

\section{Author details}

'Gazi University Faculty of Dentistry Department of Endodontics, 8. Cadde 82. Sokak, 06510 Emek-Ankara, Turkey. ${ }^{2}$ Gazi University Faculty of Dentistry Department of Restorative Dentistry, Ankara, Turkey. ${ }^{3}$ Bilecik Şeyh Edebali University Faculty of Art \& Science Department of Chemistry, Bilecik, Turkey. 
${ }^{4}$ Gazi University Faculty of Art \& Science Department of Chemistry, Ankara, Turkey.

Received: 29 September 2014 Accepted: 8 June 2015

Published online: 26 June 2015

\section{References}

1. Lee SJ, Wu MK, Wesselink PR. The effectiveness of syringe irrigation and ultrasonics to remove debris from simulated irregularities within prepared root canal walls. Int Endod J. 2004;37:672-8.

2. Haapasalo M, Endal U, Zandi H, Coil JM. Eradication of endodontic infection by instrumentation and irrigation solutions. Endod Topics. 2005;10:77-102.

3. Baugh $\mathrm{D}$, Wallace J. The role of apical instrumentation in root canal treatment: a review of the literature. J Endod. 2005;31:333-40.

4. Marending M, Luder HU, Brunner TJ, Knecht S, Stark WJ, Zehnder M. Effect of sodium hypochlorite on human root dentine-mechanical, chemical and structural evaluation. Int Endod J. 2007:40:786-93.

5. Spanó JC, Barbin EL, Santos TC, Guimarães LF, Pécora JD. Solvent action of sodium hypochlorite on bovine pulp and physico-chemical properties of resulting liquid. Braz Dent J. 2001;12:154-7.

6. Sirtes G, Waltimo T, Schaetzle M, Zehnder M. The effects of temperature on sodium hypochlorite short-term stability, pulp dissolution capacity, and antimicrobial efficacy. J Endod. 2005;31:669-71.

7. Chow TW. Mechanical effectiveness of root canal irrigation. J Endod. 1983;11:475-9.

8. Jiang LM, Lak B, Eijsvogels LM, Wesselink P, van der Sluis LW. Comparison of the cleaning efficacy of different final irrigation techniques. J Endod. 2012;38:838-41.

9. Lee SJ, Wu MK, Wesselink PR. The efficacy of ultrasonic irrigation to remove artificially placed dentin debris from different sized simulated plastic root canals. Int Endod J. 2004;37:607-12.

10. Goldman M, Kronman JH, Goldman LB, Clausen H, Grady J. New method of irrigation during endodontic treatment. J Endod. 1976;2:257-60.

11. Abou-Rass M, Piccinino MV. The effectiveness of four clinical irrigation methods on the removal of root canal debris. Oral Surg Oral Med Oral Pathol. 1982:54:323-8.

12. Sedgley CM, Nagel AC, Hall D, Applegate B. Influence of irrigant needle depth in removing bioluminescent bacteria inoculated into instrumented root canals using real-time imaging in vitro. Int Endod J. 2005;38:97-104.

13. Mitchell RP, Baumgartner JC, Sedgley CM. Apical extrusion of sodium hypochlorite using different root canal irrigation systems. J Endod. 2011;37:1677-81.

14. Weller RN, Brady JM, Bernier WE. Efficacy of ultrasonic cleaning. J Endod. 1980;6:740-3.

15. Ahmad M, Pitt Ford TJ, Crum LA. Ultrasonic debridement of root canals: aninsight into the mechanisms involved. J Endod. 1987;13:490-9.

16. Huque J, Kota K, Yamaga M, Iwaku M, Hoshino E. Bacterial eradication from root dentine by ultrasonic irrigation with sodium hypochlorite. Int Endod J. 1998;31:242-50.

17. Gutarts R, Nusstein J, Reader A, Beck M. In vivo debridement efficacy of ultrasonic irrigation following hand rotary instrumentation in human mandibular molars. J Endod. 2005;31:166-70.

18. Levy G, Rizoiu L, Friedman S, Lam H. Pressure waves in root canals induced by Nd:YAG laser. J Endod. 1996;22:81-4.

19. Blanken JW, Verdaasdonk RM. Cavitation as a working mechanism of the Er, Cr:YSGG laser in endodontics: a visualization study. J Oral Laser Appl. 2007;7:97-106

20. George R, Walsh LJ. Apical extrusion of root canal irrigants when using Er:YAG and Er, Cr:YSGG lasers with optical fibers: an in vitro dye study. J Endod. 2008;34:706-8.

21. George R, Meyers IA, Walsh $L$. Laser activation of endodontic irrigants with improved conical laser fiber tips for removing smear layer in the apical third of the root canal. J Endod. 2008;34:1524-7.

22. Hmud R, Kahler WA, George R, Walsh LJ. Cavitational effects in aqueous endodontic irrigants generated by near-infrared lasers. J Endod. 2010;36:275-8.

23. Mancini M, Cerroni L, lorio L, Armellin E, Conte G, Cianconi L. Smear layer removal and canal cleanliness using different irrigation systems (EndoActivator, EndoVac, and passive ultrasonic irrigation): field emission scanning electron microscopic evaluation in an in vitro study. J Endod. 2013;39:1456-60
24. Pasha C: Studies on new reagents for the spectrophotometric determination of anions, metals and drugs. Doctorate Thesis. Mangalore University Department of Post Graduate Studies and Research in Chemistry, India, 2008.

25. Rodríguez-Figueroa C, McClanahan SB, Bowles WR. Spectrophotometric determination of irrigant extrusion using passive ultrasonic irrigation, EndoActivator, or syringe irrigation. J Endod. 2014;40:1622-6.

26. Meire MA, Poelman D, De Moor RJ. Optical properties of root canal irrigants in the 300-3,000-nm wavelength region. Lasers Med Sci. 2014;29:1557-62.

27. Lauterborn W, Ohl CD. Cavitation bubble dynamics. Ultrason Sonochem. 1997:4:65-75.

28. de Groot SD, Verhaagen B, Versluis M, Wu MK, Wesselink PR, van der Sluis LW. Laser-activated irrigation within root canals: cleaning efficacy and flow visualization. Int Endod J. 2009;42:1077-83.

29. Malentacca A, Uccioli U, Zangari D, Lajolo C, Fabiani C. Efficacy and safety of various active irrigation devices when used with either positive or negative pressure: an in vitro study. J Endod. 2012;38:1622-6.

30. Boutsioukis C, Psimma Z, Kastrinakis E. The effect of flow rate and agitation technique on irrigant extrusion ex vivo. Int Endod J. 2014;47:487-96.

\section{Submit your next manuscript to BioMed Central and take full advantage of:}

- Convenient online submission

- Thorough peer review

- No space constraints or color figure charges

- Immediate publication on acceptance

- Inclusion in PubMed, CAS, Scopus and Google Scholar

- Research which is freely available for redistribution 